\title{
Subcutaneous Interferon- $\beta 1 a$ Does Not Increase the Risk of Stroke in Patients with Multiple Sclerosis: Analysis of Pooled Clinical Trials and Post-Marketing Surveillance
}

\author{
Meritxell Sabidó · Saritha Venkatesh • Brooke Hayward • \\ Julie Aldridge $\cdot$ Alan Gillett
}

Received: June 29, 2018 / Published online: September 25, 2018

(C) The Author(s) 2018

\section{ABSTRACT}

Introduction: Previous studies suggest that multiple sclerosis (MS) patients have a greater stroke risk than the general population but there is limited evidence of stroke risk in patients receiving disease-modifying treatment. We assessed stroke risk in MS patients treated with subcutaneous interferon- $\beta 1 \mathrm{a}$ (sc IFN- $\beta 1 \mathrm{a}$ ) using pooled data from clinical trials and postmarketing surveillance.

Methods: Seventeen phase II-IV Merck KGaAsponsored trials of sc IFN- $\beta 1 \mathrm{a}$ were assessed to estimate the stroke incidence rate (IR) and IR ratio (IRR) per 100 patient-years (PY), and associated 95\% confidence intervals (CI). The association of treatment duration with stroke was

Enhanced digital content To view enhanced digital content for this article go to https://doi.org/10.6084/ m9.figshare.7047689.

M. Sabidó $(\square)$

Merck KGaA, Darmstadt, Germany

e-mail: meritxell.sabido-espin@merckgroup.com

S. Venkatesh

EMD Serono Inc., Rockland, MA, USA

B. Hayward · J. Aldridge

EMD Serono Inc., Billerica, MA, USA

A. Gillett

EMD Serono Inc., Mississauga, ON, Canada assessed through a Cox model. IR, IRR, and hazard ratio (HR) were adjusted by age, sex, presence of any comorbidity, and MS duration. Individual case safety reports were retrieved from the Global Patient Safety Database. The reporting rates of stroke were calculated and classified as medically confirmed or non-medically confirmed according to the source of each report.

Results: In 17 clinical trials, 4412 patients were treated with sc IFN- $\beta 1$ a for a total of 10,622 PY and 1055 patients with placebo for $2005 \mathrm{PY}$. The IR/100 PY (95\% CI) of stroke was 0.025 $(0.004,0.150)$ in sc IFN- $\beta 1$ a patients and 0.051 $(0.008,0.349)$ in placebo patients. The IRR for sc IFN- $\beta 1 \mathrm{a}$ vs placebo was $0.486(0.238,0.995)$ and the HR was $0.496(0.235,1.043)$ for time to stroke-related event for sc IFN- $\beta 1$ a treatment at any dose compared with placebo. Among sc IFN- $\beta 1$ a patients, the IRR in those treated for $<2$ years was $0.602(0.159,2.277)$ and for $\geq 2$ years $0.469(0.196,1.124)$. Analysis of the safety database showed that the overall reporting rate for stroke was 13.286/10,000 PY.

Conclusion: Safety data from both clinical trial and post-marketing settings indicate that treatment with sc IFN- $\beta 1$ a does not increase stroke risk in patients with MS.

Funding: Merck KGaA, Darmstadt, Germany.

Keywords: Subcutaneous interferon- $\beta 1 \mathrm{a}$; Risk; Multiple sclerosis; Neurology; Stroke 


\section{INTRODUCTION}

Multiple sclerosis (MS) is an immune-mediated disorder of the central nervous system (CNS) caused by inflammatory demyelination that leads to the progression of neurologic disability. The most common MS disease course is relapsing-remitting MS (RRMS), which is characterized by distinct attacks of neurological symptoms followed by periods of complete or partial remission [1].

Comorbidity is an area of growing interest for patients with MS as evidence suggests that comorbidity contributes to disability progression, reduced quality of life, and diagnostic complications [2]. A meta-analysis of population-based studies showed that stroke was one of the comorbidities with the highest incidence in patients with MS [3].

A stroke occurs when the supply of blood to the brain is inhibited, depriving the brain of oxygen and resulting in brain cell death [4]. The incidence of stroke in several European countries and the USA ranges from 114 to 350 cases per 100,000 persons per year, while its prevalence ranges from $1.5 \%$ to $3 \%$ [4]. In a metaanalysis that included two population-based studies, the incidence of any stroke in patients with MS was estimated at 2.73 per 100,000 [95\% confidence interval (CI) 2.51, 2.95], with moderate heterogeneity between studies $\left(I^{2} 47.7\right)$, and the prevalence was 3.28 per $100,000(95 \%$ CI $0,8.98 ; I^{2}$ 97.4) [5-7]. In both studies the incidence of any stroke and ischemic stroke was greater in patients with MS compared with the general population. Several further studies have also shown that compared to the general population, there is a higher prevalence of any stroke or ischemic stroke in the MS population [8-11]. Multiple reports of cerebral venous thrombosis (CVT) in patients with MS have also been made; however, the pathogenesis underlying the occurrence of CVT in MS patients remains unclear. Most of the cases reported underwent a lumbar puncture and intravenous corticosteroid treatment a few days before the clinical presentation of CVT. The use of oral contraceptives, a risk factor for CVT, may also have played a role [12-15].
It has been suggested that the risk for overall stroke is increased in patients with MS during the initial year of diagnosis [6, 16, 17]. Furthermore, two of these studies showed that this increased risk persists beyond the first year, albeit at a rate that is lower than for the initial year $[6,17]$.

Beta interferons (IFN) have shown effectiveness at treating RRMS during large randomized clinical trials by reducing the frequency of exacerbations and inhibiting disability progression as assessed by sustained change on the Expanded Disability Status Scale. They are widely prescribed and are generally well tolerated with a well-established, favorable safety profile [18-21]. However, to date, only one population-based study using health administrative data in British Columbia has evaluated the risk of stroke in patients treated with IFN- $\beta$ (all formulations) [22].

The aim of this study was to assess the risk of stroke in MS patients treated with sc IFN- $\beta 1$ a and its association with treatment duration using pooled data from clinical trials and postmarketing surveillance.

\section{METHODS}

This study presents analyses of pooled data from sc IFN- $\beta 1$ a clinical trials and data from the Global Patient Safety Database.

This article is based on previously conducted studies and does not contain data collected by any of the authors.

\section{Pooled Data From sc IFN-ק1a Clinical Trials}

Data from 17 Merck-KGaA-sponsored phase II-IV trials on sc IFN- $\beta 1$ a for MS were pooled for evaluation (Table 1). Data from trials were included in this analysis regardless of MS subtype (clinically isolated syndrome, RRMS, primary progressive MS, and secondary progressive MS), sc IFN- $\beta 1$ a dose, formulation, or follow-up duration. Patients receiving other interferon formulations were excluded.

In order to summarize patient characteristics without duplication, patients were stratified 
Table 1 Main characteristics of key clinical trials included in the pooled analysis

\begin{tabular}{|c|c|c|c|c|c|c|}
\hline $\begin{array}{l}\text { Study number, } \\
\text { acronym }\end{array}$ & Design & $\begin{array}{l}\text { Placebo } \\
\text { arm }\end{array}$ & sc IFN- $\beta 1 \mathrm{a}$ & Study duration & 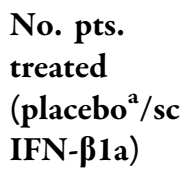 & $\begin{array}{l}\text { MS } \\
\text { subtype }\end{array}$ \\
\hline $\begin{array}{l}\text { Data on file, Merck } \\
\text { KGaA Study } \\
6613\end{array}$ & $\begin{array}{l}\text { Randomized, open- } \\
\text { label study with } \\
6 \text { months } \\
\text { untreated lead-in } \\
\text { followed by } \\
6 \text { months of } \\
\text { treatment }\end{array}$ & No & $\begin{array}{l}\text { sc IFN- } \beta 1 \mathrm{a} \\
11 \mu \mathrm{g} \text { or } \\
33 \mu \mathrm{g} \text { tiw }\end{array}$ & 1 year & $0 / 68$ & RRMS \\
\hline $\begin{array}{l}\text { Data on file, Merck } \\
\text { KGaA Study } \\
8000 \text { Extension }\end{array}$ & $\begin{array}{l}\text { Extension study of } \\
6613\end{array}$ & No & $\begin{array}{l}\text { sc IFN- } \beta 1 \mathrm{a} \\
11 \mu \mathrm{g} \text { or } \\
33 \mu \mathrm{g} \text { tiw }\end{array}$ & 18 months & & RRMS \\
\hline 7480 ETOMS [26] & $\begin{array}{l}\text { Randomized, } \\
\text { double-blind, } \\
\text { placebo-controlled }\end{array}$ & Yes & $\begin{array}{r}\text { sc IFN- } \beta 1 \mathrm{a} \\
22 \mu \mathrm{g} \mathrm{qw}\end{array}$ & $\begin{array}{l}2 \text { years; } \\
\text { 2-year extensions }\end{array}$ & $154 / 154$ & CIS \\
\hline 6789 PRISMS [18] & $\begin{array}{l}\text { Randomized, } \\
\text { double-blind, } \\
\text { placebo-controlled }\end{array}$ & $\begin{array}{l}\text { Yes, } \\
\text { option } \\
\text { to } \\
\text { switch }\end{array}$ & $\begin{array}{c}\text { sc IFN- } \beta 1 \mathrm{a} \\
22 \mu \mathrm{g} \text { or } \\
44 \mu \mathrm{g} \text { tiw }\end{array}$ & 2 years & $187 / 373$ & RRMS \\
\hline $\begin{array}{l}22930 \text { Long-term } \\
\text { follow-up } \\
\text { (LTFU) of study } \\
6789 \text { (PRISMS) } \\
\text { [27] }\end{array}$ & $\begin{array}{l}\text { Open-label, single } \\
\text { visit between year } \\
8 \text { and } 9 \text { of original } \\
\text { treatment in } \\
\text { PRISMS }\end{array}$ & $\begin{array}{l}\text { No, } \\
\text { switch } \\
\text { from } \\
6789\end{array}$ & $\begin{array}{l}\text { Any } \\
\text { commercial } \\
\text { treatment or } \\
\text { off } \\
\text { treatment at } \\
\text { LTFU visit }\end{array}$ & 8 -year extension & & RRMS \\
\hline 7999 OWIMS [28] & $\begin{array}{l}\text { Randomized, } \\
\text { double-blind, } \\
\text { placebo-controlled }\end{array}$ & Yes & $\begin{array}{c}\text { sc IFN- } \beta 1 \mathrm{a} \\
22 \mu \mathrm{g} \text { or } \\
44 \mu \mathrm{g} \text { qw }\end{array}$ & $\begin{array}{l}48 \text { weeks; } \\
\text { 2-year extension }\end{array}$ & $100 / 193$ & RRMS \\
\hline $\begin{array}{l}6954 \text { SPECTRIMS } \\
\text { [29] }\end{array}$ & $\begin{array}{l}\text { Randomized, } \\
\text { double-blind, } \\
\text { placebo-controlled }\end{array}$ & Yes & $\begin{array}{c}\text { sc IFN- } \beta 1 \mathrm{a} \\
22 \mu \mathrm{g} \text { or } \\
44 \mu \mathrm{g} \text { tiw }\end{array}$ & $\begin{array}{l}3 \text { years; } \\
\text { 3-year extension }\end{array}$ & $205 / 413$ & SPMS \\
\hline $\begin{array}{l}\text { 6976 Nordic SPMS } \\
\text { [30] }\end{array}$ & $\begin{array}{l}\text { Randomized, } \\
\text { double-blind, } \\
\text { placebo-controlled }\end{array}$ & $\begin{array}{l}\text { Yes, } \\
\text { switch } \\
\text { to } \\
22 \mu \mathrm{g}\end{array}$ & $\begin{array}{l}\text { sc IFN- } \beta 1 \mathrm{a} \\
22 \mu \mathrm{g}\end{array}$ & $\begin{array}{l}3 \text { years, } 1 \text {-year } \\
\text { extension; } 44 \mu \mathrm{g} \text { tiw } \\
\text { offered to all } \\
\text { extension II (no data } \\
\text { from II) }\end{array}$ & $178 / 186$ & SPMS \\
\hline
\end{tabular}


Table 1 continued

\begin{tabular}{|c|c|c|c|c|c|c|}
\hline $\begin{array}{l}\text { Study number, } \\
\text { acronym }\end{array}$ & Design & $\begin{array}{l}\text { Placebo } \\
\text { arm }\end{array}$ & sc IFN- $\beta 1 a$ & Study duration & 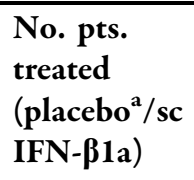 & $\begin{array}{l}\text { MS } \\
\text { subtype }\end{array}$ \\
\hline $\begin{array}{l}21125 \\
\text { EVIDENCE } \\
{[31]}\end{array}$ & $\begin{array}{l}\text { Randomized, open- } \\
\text { label, assessor- } \\
\text { blinded, parallel- } \\
\text { group study, } \\
\text { comparative }\end{array}$ & No & $\begin{array}{l}\text { sc IFN- } \beta 1 \mathrm{a} \\
44 \mu \mathrm{g} \text { tiw }\end{array}$ & $\begin{array}{l}48 \text { weeks; extension } \\
\text { (up to } 45 \text { weeks } \\
\text { post-transition) }\end{array}$ & $0 / 339$ & RRMS \\
\hline $\begin{array}{l}24735 \text { REGARD } \\
{[32]}\end{array}$ & $\begin{array}{l}\text { Randomized, open- } \\
\text { label, parallel- } \\
\text { group study, } \\
\text { comparative }^{c}\end{array}$ & No & $\begin{array}{l}\text { sc IFN- } \beta 1 \mathrm{a} \\
44 \mu \mathrm{g} \text { tiw }\end{array}$ & 96 weeks & $0 / 383$ & RRMS \\
\hline \multicolumn{7}{|c|}{ Rebif $^{\circledR}$ New Clone (484-39)-/Rebif ${ }^{\circledR}$ New Formulation (RNF; HSA-free formulation) } \\
\hline $\begin{array}{l}\text { 24810, r-hIFN } \\
\text { Beta-1a }\left(\text { Rebif }^{\circledR}\right) \\
\text { Using Clone } \\
\text { 484-39 EMEA } \\
\text { NABs } \\
\text { (NCT00367484) }\end{array}$ & $\begin{array}{l}\text { Single-arm, open- } \\
\text { label }\end{array}$ & No & $\begin{array}{l}\text { sc IFN- } \beta 1 \mathrm{a} \\
22 \mu \mathrm{g} \text { or } \\
44 \mu \mathrm{g} \text { tiw }\end{array}$ & 48 weeks & $0 / 460$ & RRMS \\
\hline $\begin{array}{l}25632 \text { The RNF } \\
\text { Study [33] }\end{array}$ & $\begin{array}{l}\text { Single-arm, open- } \\
\text { label, historical } \\
\text { comparison }\end{array}$ & No & $\begin{array}{l}\text { sc IFN- } \beta 1 \mathrm{a} \\
44 \mu \mathrm{g} \text { tiw }\end{array}$ & 96 weeks & $0 / 260$ & RRMS \\
\hline $\begin{array}{l}\text { 27025 REFLEX } \\
{[21]}\end{array}$ & $\begin{array}{l}\text { Randomized, } \\
\text { double-blind, } \\
\text { placebo-controlled }\end{array}$ & Yes & $\begin{array}{l}\text { sc IFN- } \beta 1 \mathrm{a} \\
44 \mu \mathrm{g} \text { tiw or } \\
\text { sc IFN- } \beta 1 \mathrm{a} \\
44 \mu \mathrm{g} \text { ow }\end{array}$ & 24 months & $171 / 344$ & CIS \\
\hline $\begin{array}{l}28981 \\
\text { REFLEXION } \\
{[34]}\end{array}$ & $\begin{array}{l}\text { Double-blind, } \\
\text { extension study to } \\
27025\end{array}$ & $\begin{array}{l}\text { Yes, } \\
\text { option } \\
\text { for } \\
\text { switch }\end{array}$ & $\begin{array}{l}\text { sc IFN- } \beta 1 \mathrm{a} \\
44 \mu \mathrm{g} \text { tiw or } \\
\text { sc IFN- } \beta 1 \mathrm{a} \\
44 \mu \mathrm{g} \text { ow }\end{array}$ & $\begin{array}{l}36 \text { months (total } \\
60 \text { months of } \\
\text { observation since } \\
\text { randomization into } \\
\text { REFLEX) }\end{array}$ & & CIS \\
\hline $\begin{array}{l}27178 \\
\text { IMPROVE [35] }\end{array}$ & $\begin{array}{l}\text { Randomized, } \\
\text { double-blind, } \\
\text { placebo-controlled }\end{array}$ & Yes & $\begin{array}{l}\text { sc IFN- } \beta 1 \mathrm{a} \\
44 \mu \mathrm{g} \text { tiw }\end{array}$ & $\begin{array}{l}16 \text { weeks, 24-week } \\
\text { extension }\end{array}$ & $60 / 120$ & RRMS \\
\hline
\end{tabular}


Table 1 continued

\begin{tabular}{|c|c|c|c|c|c|c|}
\hline $\begin{array}{l}\text { Study number, } \\
\text { acronym }\end{array}$ & Design & $\begin{array}{l}\text { Placebo } \\
\text { arm }\end{array}$ & sc IFN- $\beta 1 a$ & Study duration & 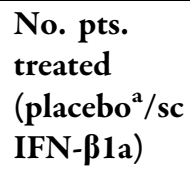 & $\begin{array}{l}\text { MS } \\
\text { subtype }\end{array}$ \\
\hline $\begin{array}{l}27571 \\
\text { TRANSFER } \\
{[36]}\end{array}$ & $\begin{array}{l}\text { Randomized, two- } \\
\text { arm, open-label }\end{array}$ & No & $\begin{array}{l}\text { sc IFN- } \beta 1 \mathrm{a} \\
44 \mu \mathrm{g} \text { tiw } \\
\text { (RNF vs. } \\
\text { original } \\
\text { formulation) }\end{array}$ & $\begin{array}{l}4 \text { weeks, 4-week safety } \\
\text { follow-up (Rebif }{ }^{\circledR} \\
\text { HSA-free } \\
\text { formulation } \\
\text { continued), and } \\
\text { long-term extension } \\
\text { (until commercial } \\
\text { availability of } \\
\text { Rebif }{ }^{\circledR} \text { HSA-free } \\
\text { formulation) }\end{array}$ & $0 / 116$ & RRMS \\
\hline $\begin{array}{l}28733 \\
\text { RebiSmart }^{\mathrm{TM}} \\
{[37]}\end{array}$ & $\begin{array}{l}\text { Single-arm, open- } \\
\text { label }\end{array}$ & No & $\begin{array}{c}\text { RNF } 44 \mu \mathrm{g} \\
\text { tiw (e- } \\
\text { device) }\end{array}$ & 12 weeks & $0 / 106$ & RRMS \\
\hline
\end{tabular}

CIS clinically isolated syndrome, RRMS relapsing-remitting multiple sclerosis, SPMS secondary progressive multiple sclerosis, $R N F$ rebif new formula, $H S A$ human serum albumin

a Includes patients who were on placebo and switched to sc IFN- $\beta 1 \mathrm{a}$

b Comparator was Avonex ${ }^{\circledR} 30 \mu \mathrm{g}$ qw, only patients randomized to start on sc IFN- $\beta 1$ a were included in this analysis

${ }^{c}$ Comparator was Copaxone ${ }^{\circledR} 20 \mu \mathrm{g}$ qd, only patients randomized to start on sc IFN- $\beta 1$ a were included in this analysis

into three groups according to the treatment received: cohort A comprised patients treated with sc IFN- $\beta 1$ a only $(n=3515)$, cohort B comprised patients treated with placebo only $(n=158)$, and cohort C comprised patients treated with placebo followed by sc IFN- $\beta 1 \mathrm{a}$ $(n=897)$. For analysis, patients who switched to sc IFN- $\beta 1$ a (cohort C) were considered as placebo patients until the start of sc IFN- $\beta 1 \mathrm{a}$ and as sc IFN- $\beta 1$ a patients following the switch. Strokerelated events that occurred before the start of sc IFN- $\beta 1 \mathrm{a}$ were analyzed alongside placeboonly events (cohort B) whereas stroke-related events that occurred after the start of sc IFN- $\beta 1$ a were analyzed alongside sc IFN- $\beta 1$ a-only events (cohort A).

Patient characteristics of the three cohorts, summarized in Table 2, included age at inclusion, sex, treatment duration (stratified in two groups: $<2$ years; $\geq 2$ years), MS disease duration in years, and baseline comorbidities, as identified from each patient's medical history, including history of prior stroke, hypertension, cardiovascular disease, diabetes, and obesity. The resulting groups used to assess the risk of stroke were those ever treated with sc IFN- $\beta 1$ a [cohort A + cohort C; $n=4412$ patients, 10,622 patient-years (PY)] and those ever treated with placebo (cohort B + cohort C; $n=1055$ patients, $2005 \mathrm{PY}$ ). The customized Standard MedDRA Query (SMQ) of central nervous system vascular disorders (20000060)_Scope Narrow for Stroke (MedDRA version 20.0) was used to retrieve 93 preferred terms corresponding to the medical concept of stroke (ischemic central nervous system vascular conditions; hemorrhagic central nervous system vascular conditions; central nervous system vascular disorders, not specified as hemorrhagic or ischemic; conditions associated with central nervous system hemorrhagic and cerebrovascular accidents). The selection was based on the underlying pathogenesis, type, etiology anatomical 
Table 2 Patient characteristics

\begin{tabular}{|c|c|c|c|}
\hline & 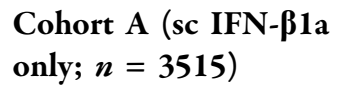 & $\begin{array}{l}\text { Cohort B (placebo } \\
\text { only; } n=158 \text { ) }\end{array}$ & $\begin{array}{l}\text { Cohort C (placebo then sc IFN- } \\
\text { B1a; } n=897 \text { ) }\end{array}$ \\
\hline Female, $n(\%)$ & $2408(68.5)$ & $105(66.5)$ & $595(66.3)$ \\
\hline Age, years & $36.92 \pm 9.34$ & $36.53 \pm 10.12$ & $36.82 \pm 9.86$ \\
\hline MS disease duration, years & $7.31 \pm 7.00$ & $7.30 \pm 8.48$ & $7.31 \pm 7.61$ \\
\hline \multicolumn{4}{|l|}{ sc IFN- $\beta 1 \mathrm{a}$ dose, $n(\%)$} \\
\hline $44 \mu \mathrm{g}$ tiw & $2343(66.7)$ & NA & $471(52.5)$ \\
\hline \multicolumn{4}{|c|}{ sc IFN- $\beta 1$ a treatment duration, $n(\%)$} \\
\hline$<2$ years & $1991(56.6)$ & NA & $493(55.0)$ \\
\hline$\geq 2$ years & $1524(43.4)$ & NA & $404(45.0)$ \\
\hline \multicolumn{4}{|c|}{ Placebo treatment duration, $n(\%)$} \\
\hline$<2$ years & NA & $107(67.7)$ & $445(49.6)$ \\
\hline$\geq 2$ years & NA & $51(32.3)$ & $452(50.4)$ \\
\hline \multicolumn{4}{|l|}{ Baseline comorbidities, $n(\%)$} \\
\hline Hypertension & $188(5.3)$ & $6(3.8)$ & $30(3.3)$ \\
\hline Diabetes mellitus & $21(0.6)$ & $1(0.6)$ & $5(0.6)$ \\
\hline Cardiovascular disorder & $1(0.0)$ & 0 & 0 \\
\hline Obesity & $62(1.8)$ & $2(1.3)$ & $7(0.8)$ \\
\hline Atrial fibrillation & $2(0.1)$ & 0 & 0 \\
\hline Carotid artery disease & 0 & 0 & 0 \\
\hline Peripheral artery disease & $22(0.6)$ & 0 & $6(0.7)$ \\
\hline Myocardial ischemia & $2(0.1)$ & 0 & $1(0.1)$ \\
\hline Cardiac failure & 0 & $1(0.6)$ & $1(0.1)$ \\
\hline $\begin{array}{l}\text { Cardiac and vascular } \\
\text { disorders congenital }\end{array}$ & $15(0.4)$ & 0 & $2(0.2)$ \\
\hline Cardiac valve disorders & $32(0.9)$ & 0 & $2(0.2)$ \\
\hline Prior stroke & $42(1.2)$ & $3(1.9)$ & $20(2.2)$ \\
\hline
\end{tabular}

Data are number $(\%)$ or mean (SD)

$M S$ multiple sclerosis, $N A$ not applicable, sc subcutaneous, $S D$ standard deviation, tiw three times weekly

location, and sequelae associated with cerebrovascular accidents.

The incidence rates (IR) of stroke per $100 \mathrm{PY}$, and associated 95\% confidence intervals (CIs), were estimated in patients who received sc IFN$\beta 1 \mathrm{a}$ and patients who received placebo using a Poisson regression model adjusted for treatment, age, sex, any comorbidities, and MS duration. The sc IFN- $\beta 1$ a group was then compared with placebo through the incidence rate ratios (IRR) and 95\% CIs. The adjusted IRR were modeled estimates based on the ratio of adjusted IR of treatment divided by adjusted IR for placebo. Hazard ratios (HR) with 95\% CI were 
calculated using a Cox regression model for stroke in patients with MS treated with sc IFN$\beta 1 \mathrm{a}$ compared to those treated with placebo. The association of stroke with dose was also assessed using a Cox regression model and the results expressed with the HR with 95\% CI. IR, IRR, and HR were all adjusted by age, sex, any comorbidity, and MS duration ( $<2$ years and $\geq 2$ years). A sensitivity analysis was performed excluding those patients with any history of prior stroke at baseline.

\section{Data From the Merck Safety Database in the Post-Marketing Setting}

The Merck KGaA Global Safety Database receives all individual case safety reports (ICSRs) reported in the post-marketing setting. ICSRs are gathered from various sources including healthcare professionals, competent authorities, patients, published case reports, and clinical trial reports. The database also records all ICSRs from clinical trials that have been classified as serious events. This corresponds to $1.7 \%$ of all events reported in the database.

This analysis comprised all ICSRs recorded cumulatively between 3 May 1998 (corresponding to the International Birth Date of sc IFN- $\beta 1 \mathrm{a})$ and the data lock point of 22 May 2017. ICSRs from patients exposed to sc IFN- $\beta 1 \mathrm{a}$ at any dose in the indication of multiple sclerosis were included from the analysis while those recorded from patients receiving placebo in clinical trials were excluded. ICSRs were included regardless of being serious or non-serious reports with event ranking and causality assessment conducted by either the reporter or Merck KGaA. The included ICSRs were categorized into two groups according to their origin: (1) medically confirmed reports received from a healthcare professional, health authority, literature case report, or clinical trial; (2) non-medically confirmed reports received from a patient or relative, either spontaneously or when solicited (i.e., provided from the company support network).

The same 93 preferred terms corresponding to the medical concept of stroke used for the analysis of pooled data from sc IFN- $\beta 1$ a clinical trials were used for the analysis of data from the safety database. The exposure of patients to sc IFN- $\beta 1 \mathrm{a}$ in the post-marketing setting was obtained from sales volume. The rate of stroke, overall and by preferred term, was calculated for patients using sc IFN- $\beta 1 \mathrm{a}$ in the post-marketing setting by dividing the number of cumulative events per 10,000 PY by exposure to sc IFN- $\beta 1$ a.

\section{RESULTS}

\section{Phase II-IV Merck KGaA-Sponsored Trials}

The baseline characteristics of 4570 patients with MS (regardless of subtype) included in the analysis of clinical trial data showed that patient demographics were similar among cohorts A, B, and C. The majority of patients were female (approximately 66.5\%) and the mean age in years was comparable among cohorts (approximately 36.5 years) (Table 2). A total of 4412 patients were treated with sc IFN$\beta 1 \mathrm{a}$ and 1055 were treated with placebo (897 were treated with both, i.e., placebo followed by sc IFN- $\beta 1$ a), for a total of 10,622 and 2005 PY (Table 3).

The adjusted IR/100 PY (95\% CI) of stroke was $0.025(0.004,0.150)$ for sc IFN- $\beta 1$ a-treated patients $(n=4412)$, and $0.051(0.008,0.349)$ for placebo-treated patients $(n=1055)$, with 25 and 11 patients reporting events in each treatment group, respectively. Compared with placebo, the adjusted IRR $(95 \% \mathrm{CI})$ for sc IFN- $\beta 1$ a was $0.486(0.238,0.995)$ for any treatment duration. The adjusted IRR (95\% CI) for sc IFN- $\beta 1$ a compared to placebo was $0.602(0.159,2.277)$ for treatment duration $<2$ years and $0.469(0.196$, $1.124)$ for $\geq 2$ years. In patients receiving sc IFN- $\beta 1 \mathrm{a} 44 \mu \mathrm{g}$ dosed three times weekly (tiw) versus placebo the IRR $(95 \% \mathrm{CI})$ was 0.436 (0.190, 0.998) (Table 3). By treatment duration, the adjusted IR (per $100 \mathrm{PY}$ ) of stroke in patients exposed to sc IFN- $\beta 1$ a for $<2$ years was 0.076 $(0.005,1.222)$ and for those $\geq 2$ years it was 0.010 (0.001, 0.104).

The adjusted HR (95\% CI) for time to strokerelated event for sc IFN- $\beta 1$ a treatment at any dose compared with placebo was 0.496 (0.235, 1.043). For sc IFN- $\beta 1 \mathrm{a} 44 \mu \mathrm{g}$ tiw, the adjusted HR 
Table 3 Incidence rate and incidence rate ratio with 95\% confidence interval for sc IFN- $\beta 1$ a relative to placebo for strokerelated event in phase II-IV Merck KGaA-sponsored trials

\begin{tabular}{|c|c|c|c|c|}
\hline & $\begin{array}{l}\text { Total exposure to } \\
\text { treatment (PY) }\end{array}$ & $\begin{array}{l}\text { Number of patients } \\
\text { with events }\end{array}$ & $\begin{array}{l}\text { Adjusted IR per } 100 \mathrm{PY} \\
(95 \% \mathrm{CI})\end{array}$ & $\begin{array}{l}\text { Adjusted IRR } \\
(95 \% \mathrm{CI})\end{array}$ \\
\hline \multicolumn{5}{|l|}{ Overall } \\
\hline Any placebo & 2005 & 11 & $0.051(0.008,0.349)$ & $0.486(0.238,0.995)$ \\
\hline Any sc IFN- $\beta 1 \mathrm{a}$ & 10621.9 & 25 & $0.025(0.004,0.150)$ & \\
\hline \multicolumn{5}{|l|}{$<2$ years } \\
\hline Any placebo & 686.8 & 3 & $0.127(0.008,2.088)$ & $0.602(0.159,2.277)$ \\
\hline Any sc IFN- $\beta 1 \mathrm{a}$ & 2849.6 & 9 & $0.076(0.005,1.222)$ & \\
\hline \multicolumn{5}{|l|}{$\geq 2$ years } \\
\hline Any placebo & 1318.1 & 8 & $0.020(0.002,0.278)$ & $0.469(0.196,1.124)$ \\
\hline Any sc IFN- $\beta 1 \mathrm{a}$ & 7772.3 & 16 & $0.010(0.001,0.104)$ & \\
\hline $44 \mu \mathrm{g}$ tiw & 5693.3 & 12 & $0.024(0.004,0.151)$ & $0.436(0.190,0.998)$ \\
\hline
\end{tabular}

Any placebo includes only time and events while on placebo for patients in cohort B and/or C (i.e., before switching to sc IFN- $\beta 1 \mathrm{a}$ ); any sc IFN- $\beta 1$ a includes time and events while on sc IFN- $\beta 1$ a for patients in cohort $\mathrm{A}$ and/or $\mathrm{C}$ (i.e., after switching to sc IFN- $\beta 1 \mathrm{a}$ )

$C I$ confidence interval, $I R$ incidence rate, $I R R$ incidence rate ratio, $P Y$ patient-years, $s c$ subcutaneous, tiw three times weekly

(95\% CI) for time to stroke-related event compared with placebo was $0.454(0.194,1.061)$ (Fig. 1).

\section{Merck Safety Database}

The customized SMQ for stroke retrieved 2039 adverse events (AE) from the Merck KGaA database of which 421 (21\%) were medically confirmed. Furthermore, of the 2039 AEs retrieved, 1345 (66\%) were serious AEs (SAE), of which 375 were medically confirmed (28\%). The estimated cumulative patient exposure to sc IFN- $\beta 1 \mathrm{a}$ in the post-marketing setting from launch until 3 May 2017 amounted to $1534,655 \mathrm{PY}$. The reporting rate by preferred term is shown in Table 4. The 2039 stroke AEs corresponded to a reporting rate of 13.286 per 10,000 PY and, the most frequently reported event corresponding to the medical concept of stroke, in patients receiving sc IFN- $\beta 1 \mathrm{a}$, was hemiparesis $(n=893)$. Of these 893 AEs, 230 were classed as SAEs and 54 of these were medically confirmed (23.5\%). The remaining
663 AEs were non-serious, of which 46 were medically confirmed (7\%).

\section{DISCUSSION}

This study assesses the risk of stroke in MS patients treated with sc IFN- $\beta 1 \mathrm{a}$ and the association between stroke and treatment duration. This is a topic of relevance as the impact of comorbidities in MS patients is becoming increasingly of interest and stroke is one of the comorbidities with the highest incidence [3]. Results from these analyses show a trend towards decreased risk of stroke for sc IFN- $\beta 1$ a compared to placebo for 4570 MS patients with 12,627 PY of follow-up clinical trial data. Further analysis was planned to estimate the impact of prior history of stroke on risk of stroke with treatment.

An increased risk of stroke with sc IFN- $\beta 1 \mathrm{a}$ was not observed during this study which was in contrast to a recent nested case-control analysis which used real-world data from a population-based health administrative 


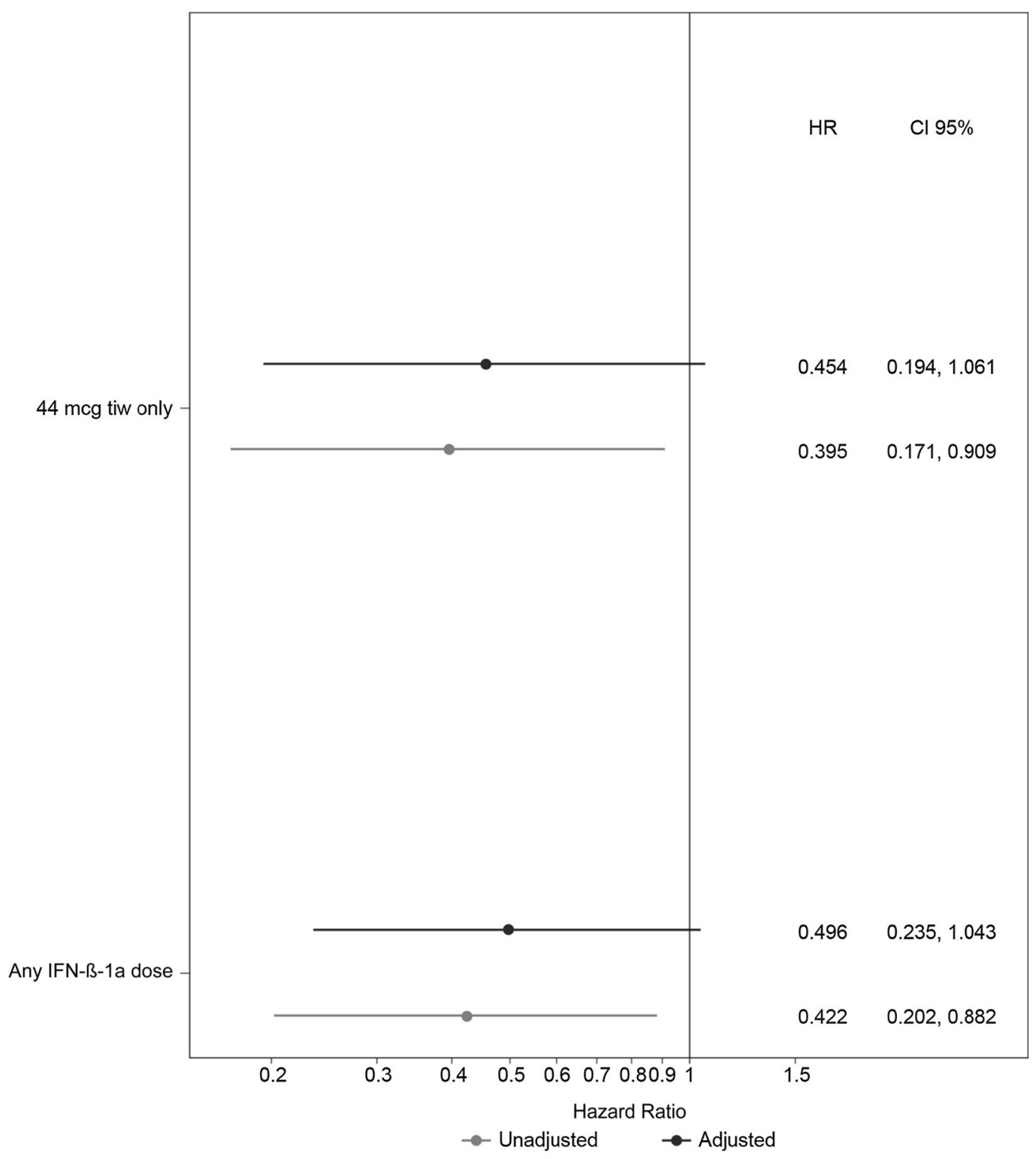

Fig. 1 Hazard ratio with 95\% confidence interval for time to stroke-related event in phase II-IV Merck KGaAsponsored trials for sc IFN- $\beta$ la treatment at any dose and at $44 \mu \mathrm{g}$ tiw compared with placebo. CI confidence interval, HR hazard ratio, tiw three times weekly. The HR

database to show that IFN- $\beta$ was associated with a 1.8-fold increase in the risk of stroke [22]. The study found that, of 2485 eligible RRMS patients, 1031 received IFN- $\beta$ (all formulations; dose and trade name not specified) and patients with incident stroke were more likely to have previous exposure to IFN- $\beta$ when compared with 95\% CIs of stroke in patients with MS are for $44 \mu \mathrm{g}$ tiw only and for any sc IFN dose with time on placebo as the reference. HR and 95\% CIs were calculated using Cox regression models and adjusted for age, sex, any comorbidities, and MS duration

with matched controls, with an adjusted odds ratio of 1.83 (95\% CI 1.16, 2.89) [22]. The mean age of the 2485 patients was 41.3 years and $77 \%$ were female; the mean follow-up was 8 years. The nested case-control analysis included all potential adverse events (selected a priori after a comprehensive literature search and defined 
Table 4 Reporting rate for most frequent serious and non-serious preferred term for stroke in patients exposed to sc IFN$\beta 1 \mathrm{a}$

\begin{tabular}{|c|c|c|c|c|c|c|c|c|}
\hline \multirow[t]{3}{*}{ Preferred term } & \multicolumn{3}{|c|}{ Serious } & \multicolumn{3}{|c|}{ Non-serious } & \multirow[t]{3}{*}{ Total } & \multirow[t]{3}{*}{ Reporting rate } \\
\hline & \multicolumn{2}{|c|}{ Medically confirmed } & \multirow[t]{2}{*}{ Total } & \multicolumn{2}{|c|}{ Medically confirmed } & \multirow[t]{2}{*}{ Total } & & \\
\hline & $\overline{\text { Yes }}$ & No & & Yes & No & & & \\
\hline Total & 375 & 970 & 1345 & 46 & 648 & 694 & 2039 & 13.286 \\
\hline Hemiparesis & 54 & 176 & 230 & 46 & 617 & 663 & 893 & 5.819 \\
\hline Cerebrovascular accident & 133 & 436 & 569 & 0 & 0 & 0 & 569 & 3.708 \\
\hline Transient ischemic attack & 28 & 127 & 155 & 0 & 1 & 1 & 156 & 1.017 \\
\hline Hemiplegia & 13 & 48 & 61 & 0 & 30 & 30 & 91 & 0.593 \\
\hline Cerebral hemorrhage & 33 & 52 & 85 & 0 & 0 & 0 & 85 & 0.554 \\
\hline
\end{tabular}

${ }^{a}$ Reporting rate calculated as number of cumulative events of stroke per 10,000 PY

with International Classification of Diseases-9/10 diagnosis codes from physician and hospital claims) in the treated patients involving at least 30 incident cases. For each case, up to 20 controls, matched by age, sex, and cohort entry year, were randomly selected from the population of patients at risk for the condition of interest [22]. The contrasting results between the nested case-control analysis and the present study may be explained in part by potential selection bias in controlled trials towards "healthier" patients through the use of prespecified criteria to exclude patients with certain comorbidities or receiving certain co-medications. However, it is important to note that the present study includes patients with different severities of MS. The nested case-control study is based on data from a claims database and it should be noted that this type of analysis is subject to limitations when compared with data from randomized controlled trials. The absolute number of individual events may have been overestimated as only one claim was used to define a possible adverse event and this could potentially have included false positives. Furthermore, potential confounders such as treatment adherence and family history of stroke were not considered. It is also important to note the differences in patient populations and sample sizes between the nested case-control analysis and the present study. The present study combines "real-world" data from the global Merck safety database with extensive data from clinical trials and includes patients regardless of MS type. The nested case-control study analyzed data from a single region and only included patients with RRMS.

The observed absence of increased stroke risk reported in the clinical trials was also reflected in the post-marketing surveillance database in which there was an overall rate of 13.286 per 10,000 PY for stroke in patients exposed to sc IFN- $\beta 1 \mathrm{a}$. The analysis found that the majority of stroke events occurred in women, which is in line with the population for MS [23].

There were no apparent trends in time to onset analysis. In most cases stroke was reported in patients also reporting underlying diseases and risk factors for development of stroke including hypertension, smoking, diabetes mellitus, and hypercholesterolemia. Importantly, in the majority of cases, treatment with IFN- $\beta$ was reported to have continued after the stroke event.

The duration of sc IFN- $\beta 1$ a treatment did not appear to impact the risk of stroke. Previous studies have shown contradictory results about the risk of stroke in patients treated with sc IFN$\beta 1$ a over time. While one study reported an increased risk of stroke in patients with $>2$ years IFN- $\beta$ exposure [22], a population-based cohort study found an increased risk of overall stroke within the first year of MS diagnosis and attributed it to surveillance bias 
(e.g., an increased frequency of neuroimaging during the initial period after multiple sclerosis diagnosis) [16]. Two studies have reported a slight and persisting risk of overall stroke over the long term $[6,17]$.

In this study, the combination of both "realworld" clinical practice data from the Merck safety database and extensive data from randomized, control trials provides a broad and robust assessment of the risk of stroke in patients treated with sc IFN- $\beta 1 \mathrm{a}$. It included a large number of trials, long follow-up, and a high number of patient years. However, clinical trial data was limited by a short follow-up of most of the placebo-controlled phases and a relatively small sample size. All data is presented "per patient years" which accounts for different exposures. Furthermore, the analysis of time to event and differentiation between less than or more than 2 years of exposure shows no increased risk. This indicates that further exposure to IFN- $\beta$ over time does not increase the risk of a stroke. Information was lacking about relevant risk factors of stroke such as smoking, dyspepsia, the use of over-the-counter medicines, or presence of restricted mobility [24]. Regarding post-marketing data, some limitations should be mentioned [25]. Passive surveillance suffers from underreporting of $\mathrm{AE}$ which might affect the accuracy of the reporting rates. Furthermore, in the surveillance system, data about patients with the same underlying condition but unexposed to sc IFN$\beta 1 \mathrm{a}$ are lacking. Information concerning the total number of doses of sc IFN- $\beta 1$ a actually administered to patients is not provided. Furthermore, it was not always possible to differentiate between causal and coincidental conditions using the Merck Safety Database and therefore the risk of stroke is likely being overreported.

\section{CONCLUSION}

The analyses of clinical trial data showed a trend towards decreased risk of stroke for sc IFN$\beta 1$ a when compared with placebo. Furthermore, there was no significant increase in risk of stroke observed in patients with short-term $(<2$ years) or long-term ( $\geq 2$ years) exposure to sc IFN- $\beta 1 \mathrm{a}$, or by dose level. Safety data from both clinical trial and post-marketing settings suggest that treatment with sc IFN- $\beta 1$ a does not increase the risk of stroke in patients with MS.

\section{ACKNOWLEDGEMENTS}

Funding. This study, the article processing charges, medical writing assistance, and the Open Access fee were all funded by Merck KGaA, Darmstadt, Germany.

Medical Writing and/or Editorial Assistance. Medical writing assistance was provided by Sean Littlewood and Simon Lancaster, inScience Communications, Springer Healthcare, Chester, UK.

Authorship. All named authors meet the International Committee of Medical Journal Editors (ICMJE) criteria for authorship for this manuscript, take responsibility for the integrity of the work as a whole, and have given final approval for the version to be published.

Disclosures. Meritxell Sabidó is an employee of Merck KGaA, Darmstadt, Germany. Saritha Venkatesh is an employee of EMD Serono Inc., a business of Merck KGaA, Darmstadt, Germany. Brooke Hayward is an employee of EMD Serono Inc., a business of Merck KGaA, Darmstadt, Germany. Julie Aldridge is an employee of EMD Serono Inc., a business of Merck KGaA, Darmstadt, Germany. Alan Gillett is an employee of EMD Serono Inc., a business of Merck KGaA, Darmstadt, Germany.

Compliance with Ethics Guidelines. This article is based on previously conducted studies and does not contain data collected by any of the authors.

Data Availability. All authors had full access to all of the data in this study and take complete responsibility for the integrity of the data and accuracy of the data analysis. All data 
generated or analyzed during this study are included in this published article.

Open Access. This article is distributed under the terms of the Creative Commons Attribution-NonCommercial 4.0 International License (http://creativecommons.org/licenses/ by-nc/4.0/), which permits any noncommercial use, distribution, and reproduction in any medium, provided you give appropriate credit to the original author(s) and the source, provide a link to the Creative Commons license, and indicate if changes were made.

\section{REFERENCES}

1. Smith AL, Cohen JA, Hua LH. Therapeutic targets for multiple sclerosis: current treatment goals and future directions. Neurotherapeutics. 2017;14(4):952-60.

2. Marrie RA, et al. Comorbidity delays diagnosis and increases disability at diagnosis in MS. Neurology. 2009;72(2):117-24.

3. Marrie RA, et al. A systematic review of the incidence and prevalence of comorbidity in multiple sclerosis: overview. Mult Scler. 2015;21(3):263-81.

4. Zhang $\mathrm{Y}$, et al. The incidence, prevalence, and mortality of stroke in France, Germany, Italy, Spain, the UK, and the US: a literature review. Stroke Res Treat. 2012;2012:436125.

5. Jadidi E, Mohammadi M, Moradi T. High risk of cardiovascular diseases after diagnosis of multiple sclerosis. Mult Scler. 2013;19(10):1336-40.

6. Christiansen CF, et al. Risk of arterial cardiovascular diseases in patients with multiple sclerosis: a population-based cohort study. Neuroepidemiology. 2010;35(4):267-74.

7. Marrie RA, et al. A systematic review of the incidence and prevalence of cardiac, cerebrovascular, and peripheral vascular disease in multiple sclerosis. Mult Scler. 2015;21(3):318-31.

8. Allen NB, et al. Vascular disease among hospitalized multiple sclerosis patients. Neuroepidemiology. 2008;30(4):234-8.

9. Kang JH, Chen YH, Lin HC. Comorbidities amongst patients with multiple sclerosis: a population-based controlled study. Eur J Neurol. 2010;17(9):1215-9.
10. Khan F, Pallant J, Brand C. Caregiver strain and factors associated with caregiver self-efficacy and quality of life in a community cohort with multiple sclerosis. Disabil Rehabil. 2007;29(16):1241-50.

11. Lavela SL, et al. Chronic diseases in male veterans with multiple sclerosis. Prev Chronic Dis. 2012;9:E55.

12. Malanga GA, Gangemi E. Intracranial venous thrombosis in a patient with multiple sclerosis. A case report and review of contraceptive alternatives in patients with disabilities. Am J Phys Med Rehabil. 1994;73(4):283-5.

13. Albucher JF, et al. Cerebral thrombophlebitis in three patients with probable multiple sclerosis. Role of lumbar puncture or intravenous corticosteroid treatment. Cerebrovasc Dis. 1999;9(5):298-303.

14. Stadler C, et al. Cerebral venous thrombosis after lumbar puncture and intravenous steroids in two patients with multiple sclerosis. Rev Neurol (Paris). 2000;156(2):155-9.

15. Vandenberghe N, et al. Cerebral venous thrombosis in four patients with multiple sclerosis. Eur J Neurol. 2003;10(1):63-6.

16. Roshanisefat $\mathrm{H}$, et al. Multiple sclerosis clinical course and cardiovascular disease risk-Swedish cohort study. Eur J Neurol. 2014;21(11):1353-e88.

17. Tseng $\mathrm{CH}$, et al. Increased risk of ischaemic stroke among patients with multiple sclerosis. Eur J Neurol. 2015;22(3):500-6.

18. PRISMS (Prevention of Relapses and Disability by Interferon beta-1a Subcutaneously in Multiple Sclerosis) Study Group. Randomised double-blind placebo-controlled study of interferon beta-1a in relapsing/remitting multiple sclerosis. Lancet. 1998;352(9139):1498-504.

19. Jacobs LD, et al. Intramuscular interferon beta-1a for disease progression in relapsing multiple sclerosis. The Multiple Sclerosis Collaborative Research Group (MSCRG). Ann Neurol. 1996;39(3):285-94.

20. The IFNB Multiple Sclerosis Study Group. Interferon beta-1b is effective in relapsing-remitting multiple sclerosis. I. Clinical results of a multicenter, randomized, double-blind, placebo-controlled trial. Neurology. 1993;43(4):655-61.

21. Comi G, et al. Comparison of two dosing frequencies of subcutaneous interferon beta-1a in patients with a first clinical demyelinating event suggestive of multiple sclerosis (REFLEX): a phase 3 randomised controlled trial. Lancet Neurol. 2012;11(1):33-41. 
22. de Jong HJI, et al. Evaluating the safety of beta-interferons in MS: a series of nested case-control studies. Neurology. 2017;88(24):2310-20.

23. Harbo HF, Gold R, Tintore M. Sex and gender issues in multiple sclerosis. Ther Adv Neurol Disord. 2013;6(4):237-48.

24. Tsau S, et al. Aspirin and multiple sclerosis. BMC Med. 2015;13(153):015-0394.

25. Sharrar RG, Dieck GS. Monitoring product safety in the postmarketing environment. Ther Adv Drug Saf. 2013;4(5):211-9.

26. Comi G, et al. Effect of early interferon treatment on conversion to definite multiple sclerosis: a randomised study. Lancet. 2001;357(9268):1576-82.

27. Kappos L, et al. Long-term subcutaneous interferon beta-1a therapy in patients with relapsing-remitting MS. Neurology. 2006;67(6):944-53.

28. The Once Weekly Interferon for MS Study Group. Evidence of interferon beta-1a dose response in relapsing-remitting MS: the OWIMS Study. Neurology. 1999;53(4):679-86.

29. Secondary Progressive Efficacy Clinical Trial of Recombinant Interferon-Beta-1a in MS (SPECTRIMS) Study Group. Randomized controlled trial of interferon-beta-1a in secondary progressive MS: clinical results. Neurology. 2001;56(11):1496-504.

30. Andersen $\mathrm{O}$, et al. Multicentre, randomised, double blind, placebo controlled, phase III study of weekly, low dose, subcutaneous interferon beta-1a in secondary progressive multiple sclerosis. J Neurol Neurosurg Psychiatry. 2004;75(5):706-10.

31. Panitch $\mathrm{H}$, et al. Randomized, comparative study of interferon beta-1a treatment regimens in MS: the
EVIDENCE Trial. Neurology. 2002;59(10):1496-506.

32. Mikol DD, et al. Comparison of subcutaneous interferon beta-1a with glatiramer acetate in patients with relapsing multiple sclerosis (the REbif vs Glatiramer Acetate in Relapsing MS Disease [REGARD] study): a multicentre, randomised, parallel, open-label trial. Lancet Neurol. 2008;7(10):903-14.

33. Giovannoni G, et al. Safety and immunogenicity of a new formulation of interferon beta-1a (Rebif New Formulation) in a phase IIIb study in patients with relapsing multiple sclerosis: 96-week results. Mult Scler. 2009;15(2):219-28.

34. Comi G, et al. Subcutaneous interferon beta-1a in the treatment of clinically isolated syndromes: 3 -year and 5-year results of the phase III dosing frequency-blind multicentre REFLEXION study. J Neurol Neurosurg Psychiatry. 2017;88(4):285-94.

35. De Stefano N, et al. Rapid benefits of a new formulation of subcutaneous interferon beta-1a in relapsing-remitting multiple sclerosis. Mult Scler. 2010;16(7):888-92.

36. Camu W, et al. Patient satisfaction following transition from the original to the new formulation of subcutaneous interferon beta- $1 \mathrm{a}$ in relapsing multiple sclerosis: a randomized, two-arm, open-label, phase IIIb study. Patient Prefer Adherence. 2010;4:127-33.

37. Devonshire $\mathrm{V}$, et al. Patient-rated suitability of a novel electronic device for self-injection of subcutaneous interferon beta- $1 \mathrm{a}$ in relapsing multiple sclerosis: an international, single-arm, multicentre, phase IIIb study. BMC Neurol. 2010;10:28. 